\title{
Evaluation of Sugarcane Leaves as a Substrate for Production of Palmitoleic Acid Using Cyberlindnera subsufficiens NG8.2
}

\author{
Patcharaporn Hoondee, ${ }^{\mathrm{a}}$ Ratchana Pranimit, ${ }^{\mathrm{a}}$ Somboon Tanasupawat, ${ }^{\mathrm{b}, \mathrm{c}}$ and \\ Ancharida Savarajara ${ }^{\text {a,c, } *}$
}

\begin{abstract}
Oil was produced from sugarcane leaves hydrolysate (SLH) in the newly isolated oleaginous yeast Cyberlindnera subsufficiens NG8.2, using a twostage cultivation method. The SLH contained sugars derived from both the dilute acid pretreatment of leaves and subsequent enzymatic hydrolysis (16.6 $\mathrm{g} / \mathrm{L}$ of glucose and $15.87 \mathrm{~g} / \mathrm{L}$ of xylose). The Cyberlindnera subsufficiens NG8.2 produced oil containing $18.73 \mathrm{wt} \%$ of palmitoleic acid, with a $0.99-\mathrm{g} / \mathrm{L}$ oil yield when grown in the SLH. Removal of phosphate from the $\mathrm{SLH}$ by $\mathrm{Ca}(\mathrm{OH})_{2}$ treatment $(\mathrm{SLH}-\mathrm{P})$ resulted in an increased oil yield of $1.38 \mathrm{~g} / \mathrm{L}$, but the palmitoleic acid content of the oil decreased to $12.45 \mathrm{wt} \%$. Supplementation of the SLH-P with $3.12 \mathrm{mM}$ of $\mathrm{Mg}^{2+}$ increased the palmitoleic acid content in the oil to $15.80 \mathrm{wt} \%$ and the oil yield to 1.58 $\mathrm{g} / \mathrm{L}$, with a palmitoleic acid yield of $2.09 \mathrm{mg} / \mathrm{g}$ sugarcane leaves. Thus, sugarcane leaves are a promising feedstock for palmitoleic acid production using Cyberlindnera subsufficiens NG8.2.
\end{abstract}

Keywords: Sugarcane leaves; Palmitoleic acid; Cyberlindnera subsufficiens; $\mathrm{Ca}(\mathrm{OH})_{2}$ treatment

Contact information: a: Department of Microbiology, Faculty of Science, Chulalongkorn University, 254 Phayathai Rd., Bangkok 10330, Thailand; b: Department of Biochemistry and Microbiology, Faculty of Pharmaceutical Sciences, Chulalongkorn University, 254 Phayathai Rd., Bangkok 10330, Thailand; c: Research Unit in Bioconversion/Bioseparation for Value-Added Chemical Production, Chulalongkorn University, 254 Phayathai Rd., Bangkok 10330, Thailand; *Corresponding author: sanchari@chula.ac.th

\section{INTRODUCTION}

Thailand is the world's fourth-largest sugarcane (Saccharum spp.) producer, with approximately 132 million metric tons of sugarcane cultivated in crop year 2019/2020 (Office of the Cane and Sugar Board 2020). This generated approximately 22.44 million metric tons of sugarcane leaves (0.17 tons leaves per ton sugarcane) (Department of Alternative Energy Development and Efficiency 2013). Most of these leaves were burnt before cane harvesting to prevent the farmers from being cut by the sharp edges of the leaves, making the cane harvesting easier. However, the burning of sugarcane leaves is a major cause of air pollution in Southeast Asia where this practice of cane harvesting is used. Value creation with the sugarcane leaves may reduce the amount of leaves that are burnt. Sugarcane leaves are high in cellulose, which can be converted to fermentable sugar. Therefore, they can serve as a low-cost fermentable sugar resource for production of various high-value products. Sugarcane leaves have previously been evaluated as feedstocks for the production of bioethanol (Jutakanoke et al. 2012) and yeast oil (Pranimit et al. 2019).

When grown under an overabundance of carbon but a deficiency of an essential nutrient (most often, nitrogen or phosphate), some yeasts that express cytosolic adenosine 
triphosphate (ATP) citrate lyase (ACL) divert the carbon from energy production via the tricarboxylic acid (TCA) cycle to lipid biosynthesis. Under a nitrogen-limiting condition, the carbon flux is initiated by adenosine monophosphate (AMP) deaminase liberation of ammonia from AMP to be utilized as a nitrogen source. Reduction of the cellular AMP level inhibits the activity of isocitrate dehydrogenase, the enzyme responsible for conversion of isocitrate to $\alpha$-ketoglutaric acid in the TCA cycle, and this results in citrate accumulation due to the equilibrium concentration between isocitrate and citrate by isocitrate aconitase in the mitochondria. The accumulated mitochondrial citrate is transported to the cytoplasm. In the cytoplasm, the citrate is then converted to acetyl coenzyme A (acetyl-CoA) and oxaloacetate by ACL, and the acetyl-CoA is then catalyzed to malonyl-CoA by acetyl-CoA carboxylase. The malonyl-CoA is catalyzed through a series of reactions, then channeled into the lipid biosynthesis pathway. Meanwhile, the oxaloacetate produced is catalyzed to malate by malate dehydrogenase, and then malic enzyme (ME) converts the malate to pyruvate (Ageitos et al. 2011; Probst et al. 2016).

Under a phosphate-limited condition, the reduction in AMP is initiated by AMP degradation in response to the need for inorganic phosphate in the cell. This reduces the isocitrate dehydrogenase activity, which is involved in citrate transportation from the mitochondria to the cytoplasm and lipid biosynthesis, as described above (Wang et al. 2018). Phosphate limitation is, therefore, effectively similar to nitrogen limitation in terms of stimulating microbial lipid production (Wu et al. 2010). Most of the lipids accumulate in the cell as triacylglycerols (TAG) and as discrete oil droplets (Ageitos et al. 2011; Probst et al. 2016).

Yeasts that accumulate oil to more than $20 \mathrm{wt} \%$ of dry cell weight (DCW) are defined as oleaginous yeasts (Ageitos et al. 2011). In general, dominant fatty acids of oleaginous yeast oils are palmitic acid, stearic acid, and oleic acid (Meesters et al. 1996) which are similar to those of common plant oils (Papanikolaou and Aggelis 2011). However, oils of some oleaginous yeasts including Pichia segobiensis SSOH12 (Schulze et al. 2014), Candida krusei DBM 2163, and Yarrowia lipolytica CCY 29-26-36 (Kolouchová et al. 2015) contained high concentration of palmitoleic acid (C16:1) or omega-7 fatty acid. These yeast oils have gained high interest due to broad applications of the palmitoleic acid in medicine and cosmetics ( Rezanka et al. 2013; Kolouchová et al. 2015).

The palmitoleic acid prevents B-cell apoptosis and type-2 diabetes (Morgan and Dhayal 2010) and reduces LDL cholesterol in blood vessels (Griel et al. 2008), leading to prevention of brain and cardiovascular diseases. Moreover, palmitoleic acid also acts as a growth inhibitor of Gram-positive bacteria (Wille and Kydonieus 2003). Sea buckthorn and macadamia nuts are only two plants with naturally high concentrations of palmitoleic acid, at approximately $12 \mathrm{wt} \%$ to $22 \mathrm{wt} \%$ (Kolouchová et al. 2015). But their availability is limited and quality of the oils is depended upon locality including climatic and seasonal conditions. The usage of yeast for oil production provides better benefits over plants as yeasts grow fast without effects from changing of climatic or seasonal condition, they do not require land space for plantation compared with plant cultivation, and it is easier to expand production (Sitepu et al. 2014). In addition, yeasts can be cultured in various carbon sources, including sugars derived from lignocellulose, and the oil so produced can be manipulated to have different fatty acid profiles (Kitcha and Cheirsilp 2011).

In this study, it is reported that sugarcane leaf hydrolysate (SLH) is a potential sustainable, renewable raw material for the production of palmitoleic acid by 
Cyberlindnera (Cy.) subsufficiens NG8.2 when the SLH is treated with $\mathrm{Ca}\left(\mathrm{OH}_{2}\right)$ and supplemented with $\mathrm{Mg}^{2+}$.

\section{EXPERIMENTAL}

\section{Microorganism}

Cyberlindnera subsufficiens NG8.2 was isolated from the soil at Ngao waterfall, Ranong province, Thailand. It was identified by molecular operational taxonomic unit (MOTU) and species inference by comparing their D1/D2 domain (500-600 bp) of 26S rRNA gene sequence with those deposited in the NCBI GenBank database using the BLASTn program as reported by Hoondee et al. (2019). The D1/D2 domain sequence of the $C y$. subsufficiens NG8.2 was submitted to the GenBank database with the accession number of LC602814. For short-term storage, Cy. subsufficiens NG8.2 was maintained by keeping the culture grown on yeast malt extract (YM) agar $(10 \mathrm{~g} / \mathrm{L}$ of glucose, $3 \mathrm{~g} / \mathrm{L}$ of yeast extract, $3 \mathrm{~g} / \mathrm{L}$ of malt extract, $5 \mathrm{~g} / \mathrm{L}$ of Bacto peptone, and $2 \mathrm{~g} / \mathrm{L}$ of agar, $\mathrm{pH} 5.5$ ) at $30{ }^{\circ} \mathrm{C}$ for $48 \mathrm{~h}$ in a refrigerator. Long-term storage of the culture was performed by lyophilization.

\section{Sugarcane Leaves}

Sugarcane (Saccharum officinarum L. CSB06-2-15) leaves were collected from the Sugarcane and Sugar Industry Promotion Center, Chonburi province, Thailand. They were sun dried, cut, hammer milled, and sieved to a particle size of 20 mesh to 40 mesh. The particles were then dried at $60{ }^{\circ} \mathrm{C}$ until reaching a constant weight and then kept in a desiccator. The chemical composition of the sugarcane leaves, as analyzed by the methods of the Technical Association of the Pulp and Paper Industry (TAPPI T221 om-02 2002; TAPPI T203 cm-99 2009; TAPPI T222 om-15 2015), is shown in Table 1.

Table 1. Chemical Composition of the Sugarcane Leaves

\begin{tabular}{|c|c|}
\hline Component & Percentage of Dry Weight (DW) (wt\%) \\
\hline Cellulose & 38.8 \\
\hline Hemicellulose & 23.5 \\
\hline Lignin & 13.8 \\
\hline Ash & 11.4 \\
\hline
\end{tabular}

\section{Oil Production by Cy. subsufficiens NG8.2}

Oil production in a high $\mathrm{C} / \mathrm{N}$ medium

Production of oil by $C y$. subsufficiens NG8.2 was performed by a two-stage cultivation method due to the different nutrient requirements in the growth and oil production phases (Lin et al. 2014). For the first stage (cell propagation), the $C y$. subsufficiens NG8.2 was inoculated into YM broth $(50 \mathrm{~mL})$ at the initial optical density at $660 \mathrm{~nm}\left(\mathrm{OD}_{660 \mathrm{~nm}}\right)$ of 0.8 in a $250-\mathrm{mL}$ Erlenmeyer flask and incubated at $30{ }^{\circ} \mathrm{C}$ and 200 rpm for $24 \mathrm{~h}$. The resultant culture (approximately OD $660 \mathrm{~nm}$ of 2.3) was transferred at 10 vol\% into $50 \mathrm{~mL}$ of fresh YM medium and incubated at the same conditions for $48 \mathrm{~h}$. The cells were then collected by centrifugation $\left(4^{\circ} \mathrm{C}, 9803 \mathrm{~g}, 10 \mathrm{~min}\right)$. For the second stage (oil production), the obtained cell pellet was washed twice with sterile distilled water and transferred into $50 \mathrm{~mL}$ of oil production medium (OPM) with a high $\mathrm{C} / \mathrm{N}$ molar ratio (50 $\mathrm{g} / \mathrm{L}$ of glucose, $0.1 \mathrm{~g} / \mathrm{L}$ of yeast extract, $0.5 \mathrm{~g} / \mathrm{L}$ of $\mathrm{MgSO}_{4} \cdot 7 \mathrm{H}_{2} \mathrm{O}, 0.1 \mathrm{~g} / \mathrm{L}$ of $\left(\mathrm{NH}_{4}\right)_{2} \mathrm{SO}_{4}$, 
$0.1 \mathrm{~g} / \mathrm{L}$ of $\mathrm{NaCl}$, and $0.1 \mathrm{~g} / \mathrm{L}$ of $\mathrm{CaCl}_{2} \cdot 2 \mathrm{H}_{2} \mathrm{O}$, pH 5.5) in a $250-\mathrm{mL}$ Erlenmeyer flask and incubated at $30{ }^{\circ} \mathrm{C}$ and $200 \mathrm{rpm}$ for $6 \mathrm{~d}$. At the indicated time, cells were harvested by centrifugation $\left(4{ }^{\circ} \mathrm{C}, 9803 \mathrm{~g}, 10 \mathrm{~min}\right)$, washed twice with distilled water, dried by lyophilization, and weighed to obtain the DCW of the resultant cell biomass.

\section{Evaluation of the intracellular oil accumulation}

The intracellular oil accumulated in the lyophilized cells was analyzed as reported by Folch et al. (1957), except with minor modification. In brief, the lyophilized cells (1.0 g DCW) were suspended in $20 \mathrm{~mL}$ of a 2:1 (v/v) chloroform : methanol mixture and sonicated at $37 \mathrm{kHz}$ (Elmasonic E60H, Elma Schmidbauer GmbH, Singen, Germany) at room temperature for $30 \mathrm{~min}$ prior to being centrifuged $\left(4^{\circ} \mathrm{C}, 5416 \mathrm{~g}\right.$, $\left.40 \mathrm{~min}\right)$. Sodium chloride solution at $0.73 \%(\mathrm{w} / \mathrm{v})$ was mixed with the resultant supernatant to obtain a 2:1:0.8 (v/v/v) chloroform : methanol : aqueous saline mixture and then centrifuged $\left(4{ }^{\circ} \mathrm{C}\right.$, $774 \mathrm{~g}, 10 \mathrm{~min}$ ). The lower phase was collected, dried by evaporation at room temperature, and weighed. The oil content (wt\% DCW) was the amount of oil extracted from $100 \mathrm{~g}$ of cells DCW, while the oil yield $(\mathrm{g} / \mathrm{L})$ was calculated from the oil content divided by 100 and then multiplied by the cell biomass $(\mathrm{g} / \mathrm{L})$.

\section{Fatty acid composition analysis}

The extracted Cy. subsufficiens NG8.2 oil was directly converted to fatty acid methyl esters, extracted by hexane, and analyzed by gas chromatography using a flame ionization detector system (6890N, Agilent Technologies, Santa Clara, CA, USA) as previously described (Pranimit et al. 2019).

\section{Preparation of the Sugarcane Leaves Hydrolysate (SLH)}

The SLH was prepared as previously described (Jutakanoke et al. 2012). In brief, the dried sugarcane leaf particles at $6 \%$ or $12 \%(\mathrm{w} / \mathrm{v})$ were suspended in $1.5 \%(\mathrm{w} / \mathrm{v})$ of sulfuric acid and autoclaved at $121{ }^{\circ} \mathrm{C}$ and $103 \mathrm{kPa}$ for $30 \mathrm{~min}$. The pretreated slurry (pretreated sugarcane leaves suspended in pretreatment hydrolysate) was adjusted to a $\mathrm{pH}$ of 5.0 and further saccharified by Accellulase ${ }^{\mathrm{TM}} 1500$ (2500 carboxymethyl cellulose (CMC) U/g, Genecor International Inc., New York, NY, USA) at $50{ }^{\circ} \mathrm{C}$ and $125 \mathrm{rpm}$ for 6 $\mathrm{h}$. Then, the solid residue was separated by filtration through a cotton sheet and centrifugation $\left(4^{\circ} \mathrm{C}, 9803 \mathrm{~g}, 20 \mathrm{~min}\right)$. The resultant filtrate (SLH) was adjusted to a $\mathrm{pH}$ of 5.5 and filter-sterilized through a $0.22-\mu \mathrm{m}$ membrane filter. The SLH obtained from the $6 \%(\mathrm{w} / \mathrm{v})$ sugarcane leaf loading $(6 \%-\mathrm{SLH})$ was used for inoculum medium preparation, while that from the $12 \%(\mathrm{w} / \mathrm{v})$ sugarcane leaf loading $(12 \%-\mathrm{SLH})$ was used as the OPM. The $12 \%$-SLH was reported to contain furfural and HMF at $0.13 \mathrm{~g} / \mathrm{L}$ and $0.3 \mathrm{~g} / \mathrm{L}$, respectively (Pranimit et al. 2019), which were lower than reported toxic level (Chen et al. 2009; Yu et al. 2011). Figure 1a shows a schematic diagram of SLH preparation.

\section{Removal of Phosphate from the SLH}

Phosphate in the $12 \%$-SLH was removed by the modified method of $\mathrm{Yu}$ et al. (2011). Calcium hydroxide $\left(\mathrm{Ca}(\mathrm{OH})_{2}\right)$ was added into the $12 \%-\mathrm{SLH}$ until the $\mathrm{pH}$ reached 10 , and the mixture was further incubated at $50{ }^{\circ} \mathrm{C}$ with $125-\mathrm{rpm}$ mixing for $30 \mathrm{~min}$. After centrifugation $\left(4^{\circ} \mathrm{C}, 9803 \mathrm{~g}, 20 \mathrm{~min}\right)$, the supernatant (phosphate-removed SLH, SLH-P) was harvested, adjusted to a $\mathrm{pH}$ of 5.5 , and filter sterilized through a $0.22-\mu \mathrm{m}$ membrane filter (Fig. 1b). 


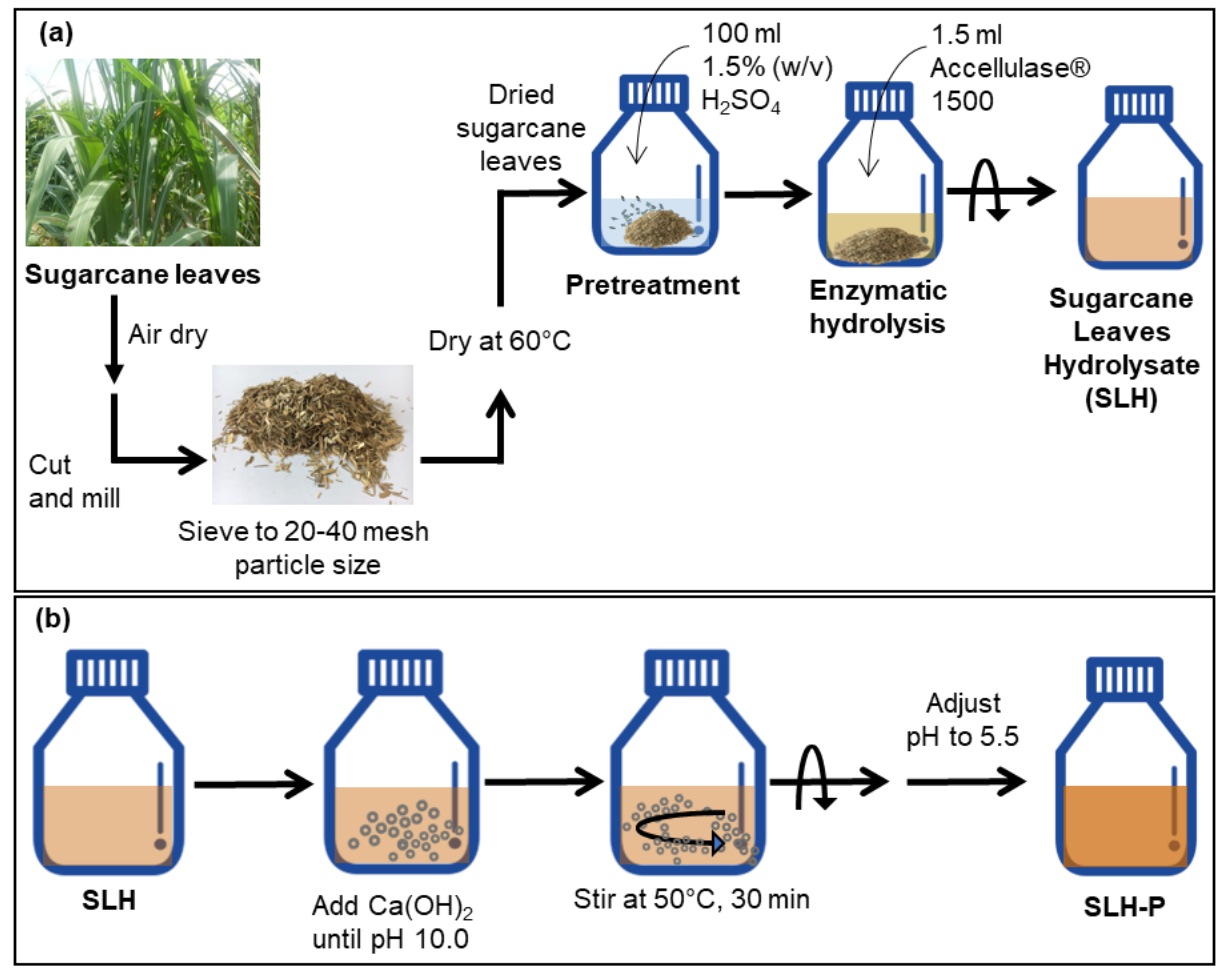

Fig. 1. Schematic diagram of the preparation of (a) SLH and (b) SLH-P

\section{Oil Production by Cy. subsufficiens NG8.2 in 12\%-SLH}

Cyberlindnera subsufficiens NG8.2 oil was produced using the same method as above, except that $6 \%$-SLH was used as the inoculum medium by supplementing with $0.3 \%$ $(\mathrm{w} / \mathrm{v})$ of yeast extract and $0.3 \%(\mathrm{w} / \mathrm{v})$ of peptone, and $12 \%-\mathrm{SLH}$ was used as the OPM.

Maximization of the oil production by Cy. subsufficiens NG8.2 in 12\%-SLH

Optimal $\mathrm{C} / \mathrm{N}$ and $\mathrm{C} / \mathrm{P}$ molar ratios of an OPM are important factors for maximization of yeast oil production (Papanikolaou and Aggelis 2011). The SLH had low $\mathrm{C} / \mathrm{N}$ molar ratio. Increase of the $\mathrm{C} / \mathrm{N}$ molar ratio by removing of nitrogen is difficult. Therefore, C/P molar ratio of the SLH was increased by removing of phosphate. Soluble phosphate can be removed by precipitation with metal ions, such as $\mathrm{Ca}^{2+}$ and $\mathrm{Mg}^{2+}$ (Kolouchová et al. 2016). Treatment with $\mathrm{Ca}(\mathrm{OH})_{2}$ (over-liming) is a popular method for removing soluble phosphate by precipitating it as $\mathrm{Ca}_{3}\left(\mathrm{PO}_{4}\right)_{2}$ (Xia et al. 2016; Bao et al. 2018). This approach has been used to remove phosphate from several lignocellulosic hydrolysates (Wu et al. 2010; Bao et al. 2018; Zhou et al. 2019). Thus, the SLH was treated with $\mathrm{Ca}(\mathrm{OH})_{2}$ to increase the $\mathrm{C} / \mathrm{P}$ molar ratio. The concentration of $\mathrm{Mg}^{2+}$ and initial $\mathrm{pH}$ of OPM, which were reported to have an influence on oleaginous yeast oil production, were also investigated (Chen et al. 2013). The activity of ACL, a key enzyme in de novo lipid accumulation, is dependent on the presence of $\mathrm{Mg}^{2+}$ (Amaretti et al. 2010). The optimum $\mathrm{pH}$ for oil production depends on the yeast strain and type of carbon source (Angerbauer et al. 2008). Generally, the optimal $\mathrm{pH}$ for oil production in yeasts ranges from 5 to 6 (Madani et al. 2017).

Maximization of the oil production by Cy. subsufficiens NG8.2 in the 12\%-SLH was performed sequentially by 1 ) increasing the $\mathrm{C} / \mathrm{P}$ molar ratio of the $12 \%-\mathrm{SLH}$ by removal of phosphate (i.e., using SLH-P); 2) increasing the C/P molar ratio of the SLH-P 
by adding glucose at $5 \mathrm{~g} / \mathrm{L}$ or $10 \mathrm{~g} / \mathrm{L} ; 3$ ) increasing the $\mathrm{Mg}^{2+}$ concentration of the selectedC/P-molar-ratio SLH-P by adding $\mathrm{MgSO}_{4} \cdot 7 \mathrm{H}_{2} \mathrm{O}$ at $0.5 \mathrm{~g} / \mathrm{L}, 0.75 \mathrm{~g} / \mathrm{L}$, or $1 \mathrm{~g} / \mathrm{L}$; and 4) varying the initial $\mathrm{pH}(4.5,5.5$, or 6$)$ of the SLH-P containing the selected concentration of $\mathrm{Mg}^{2+}$.

Palmitoleic acid yield (mg/g DW sugarcane leaves) was calculated by multiplication of the palmitoleic acid content (wt\%) with the oil yield $(\mathrm{g} / \mathrm{L})$ and then divided by 12 .

\section{Analytical Procedures}

The concentrations of glucose and xylose were analyzed using a biochemistry analyzer (YSI 2700 Select, YSI Incorporated, Yellow Springs, OH, USA). Total nitrogen was analyzed by the Kjeldahl method (Kjeldahl 1883), while the concentrations of galactose, arabinose, and cellobiose were determined by high-performance liquid chromatography using a monosaccharide column (Rezex ${ }^{\mathrm{TM}}$ RPM, Phenomenex, Torrance, CA, USA) and an evaporative light scattering detector (Agilent Technologies, Santa Clara, CA, USA) at the Scientific and Technological Research Equipment Centre, Chulalongkorn University, Bangkok, Thailand. The orthophosphate concentration was determined by the ascorbic acid method 4500-PE, as reported by Rice et al. (2012), while the concentrations of calcium, magnesium, potassium, zinc, copper, iron, and manganese were determined by atomic absorption spectrometry, as reported by Rice et al. (2012) at the Environmental Research Institute, Chulalongkorn University, Bangkok, Thailand.

\section{RESULTS AND DISCUSSION}

\section{Oil Production by Cy. subsufficiens NG8.2 in a High C/N Medium and Its Fatty Acid Composition}

The Cy. subsufficiens NG8.2 had high oil yield (1.26 g/L), oil content (20.12 wt\% of DCW), and cell biomass $(6.31 \mathrm{~g} / \mathrm{L})$ when grown in the high C/N OPM. To the authors' knowledge, this is the first report that $C y$. subsufficiens is oleaginous. Previous reports have included $C y$. subsufficiens C6.1 isolated from coconut producing fruity aromatic compounds in non-alcoholic beer (Bellut et al. 2019) and Cy. subsufficiens DMKUYNB42-1, a high-ethanol-producing yeast (Jaiboon et al. 2016).

Analysis of the Cy. subsufficiens NG8.2 oil produced in the high C/N OPM revealed that the dominant fatty acids were oleic (C18:1), palmitic (C16:0), palmitoleic (C16:1), and linoleic (C18:2) acids at $34.64 \mathrm{wt} \%, 26.32 \mathrm{wt} \%, 22.25 \mathrm{wt} \%$, and $12.21 \mathrm{wt} \%$, respectively. Other fatty acids found in lesser amounts $(0.52 \mathrm{wt} \%$ to1.89 wt\%) were myristic (C14:0), steric (C18:0), and linolenic (C18:3) acids (Table 2 ). The major fatty acids normally found in oleaginous yeast oils are oleic, palmitic, stearic, and linoleic acids (Sitepu et al. 2014). Only a few oleaginous yeasts produce oil high in palmitoleic acid. Schulze et al. (2014) reported that Pichia segobiensis SSOH12 oil contained $16 \mathrm{wt} \%$ of palmitoleic acid, while the oils from Candida krusei DBM 2163 and Yarrowia lipolytica CCY 29-26-36 contained $16.0 \mathrm{wt} \%$ and $16.4 \mathrm{wt} \%$ of palmitoleic acid, respectively, when grown in an OPM containing $30 \mathrm{~g} / \mathrm{L}$ of glucose with a $\mathrm{C} / \mathrm{N}$ molar ratio of 30 and a $\mathrm{C} / \mathrm{P}$ molar ratio of 6 (Kolouchová et al. 2015).

Table 2. Fatty Acid Profile of $C y$. subsufficiens NG8.2 Oil Produced in a High C/N 
OPM

\begin{tabular}{|c|c|}
\hline Fatty Acid & Percentage (wt\%) \\
\hline Myristic acid (C14:0) & $0.52 \pm 0.00$ \\
\hline Palmitic acid (C16:0) & $26.32 \pm 0.02$ \\
\hline Palmitoleic acid (C16:1) & $22.25 \pm 0.14$ \\
\hline Steric acid (C18:0) & $0.69 \pm 0.06$ \\
\hline Oleic acid (C18:1 n9) & $34.64 \pm 0.06$ \\
\hline Linoleic acid (C18:2 n6) & $12.21 \pm 0.02$ \\
\hline Linolenic acid (C18:3 n3) & $1.89 \pm 0.00$ \\
\hline Others & 1.48 \\
\hline Data are shown as the mean \pm SD, derived from three independent repeats. \\
\hline
\end{tabular}

\section{Oil Production by Cy. subsufficiens NG8.2 in 12\%-SLH}

The Cy. subsufficiens NG8.2 gave the highest oil yield of $0.99 \mathrm{~g} / \mathrm{L}$, which was lower than in the high C/N OPM after $4 \mathrm{~d}$ of incubation at $30{ }^{\circ} \mathrm{C}$ and $200 \mathrm{rpm}$ in the SLH OPM, while the oil content and cell biomass were $9.82 \mathrm{wt} \%$ of DCW and $10.04 \mathrm{~g} / \mathrm{L}$, respectively. The SLH had a slightly lower carbon level but substantially greater nitrogen and phosphate levels than the high C/N OPM (Table 3). This might be a reason why the Cy. subsufficiens NG8.2 produced lower oil yield in the SLH OPM than the high C/N OPM.

Table 3. Comparison of the Compositions of the High C/N Medium, SLH, and SLH-P Oil Production Media

\begin{tabular}{|c|c|c|c|}
\hline Composition & High C: $\mathbf{~ N}^{\mathbf{a}}$ & SLH & SLH-P \\
\hline g/L & & & $15.43 \pm 0.1$ \\
\hline Glucose & 50 & $16.6 \pm 0.08$ & $14.9 \pm 0.00$ \\
\hline Xylose & - & $15.87 \pm 0.05$ & 0.36 \\
\hline Galactose & - & 0.36 & 3.73 \\
\hline Arabinose & - & ND & ND \\
\hline Cellobiose & - & 36.46 & 34.42 \\
\hline Total sugar & 50 & & 1.9 \\
\hline mg/L & & 2.5 & 1170 \\
\hline Magnesium (Mg) & 49.375 & 1260 & 536 \\
\hline Potassium (K) & 0.0319 & 362 & 0.79 \\
\hline Calcium (Ca) & 27.203 & 1.3 & 0.62 \\
\hline Iron (Fe) & 0.0055 & 7.5 & $<0.01$ \\
\hline Manganese (Mn) & - & $<0.1$ & 0.85 \\
\hline Copper (Cu) & - & 1.8 & 0.014 \\
\hline Zinc (Zn) & - & 75.7 & 13.77 \\
\hline Phosphate (PO 4$)$ & 3.27 & & 0.5 \\
\hline g/L & & 14.58 & 27.54 \\
\hline Total C & 20.0 & 0.6 & $21,182.07$ \\
\hline Total Nitrogen & 0.32 & 194.20 & \\
\hline C/N molar ratio & 626.97 & & \\
\hline C/P molar ratio & $18,744.61$ & & \\
\hline a Calculated data, ND (not detectable) & & & \\
\hline & & & \\
\hline
\end{tabular}

\section{Maximization of Cy. subsufficiens NG8.2 Oil Production in 12\%-SLH}


As shown in Table 3, the phosphate concentration in the SLH $(75.7 \mathrm{mg} / \mathrm{L})$ was decreased by $99.98 \%$ to $14 \mu \mathrm{g} / \mathrm{L}$ in the SLH-P, while the total sugar concentration in the SLH (36.46 g/L) was also decreased by $5.6 \%$ to $34.42 \mathrm{~g} / \mathrm{L}$ in the SLH-P. After removal of phosphate, the C/P molar ratio of the SLH increased from 194 to 21,182 in the SLH-P. The total nitrogen concentration of the SLH $(0.6 \mathrm{~g} / \mathrm{L})$ was also decreased, to $0.5 \mathrm{~g} / \mathrm{L}$ in the SLH$\mathrm{P}$, leading to an increased C/N molar ratio from 24.31 in the SLH to 27.54 in the SLH-P. This result is in accord with previous studies, where the sugar and nitrogen concentrations of $\mathrm{Ca}(\mathrm{OH})_{2}$-treated Jerusalem artichoke hydrolysate were slightly lower than in the untreated hydrolysate, and the $\mathrm{C} / \mathrm{N}$ molar ratio of the untreated hydrolysate (29) increased to 35 in the $\mathrm{Ca}(\mathrm{OH})_{2}$-treated hydrolysate (Bao et al. 2018).

When grown in the SLH-P at $30{ }^{\circ} \mathrm{C}$ and $200 \mathrm{rpm}$ for $4 \mathrm{~d}$, the Cy. subsufficiens NG8.2 gave an oil yield of $1.38 \mathrm{~g} / \mathrm{L}$, which was $39 \%$ higher than in the SLH, with an oil content and cell biomass of $13.20 \mathrm{wt} \%$ of DCW and $10.45 \mathrm{~g} / \mathrm{L}$, respectively (Fig. 2).

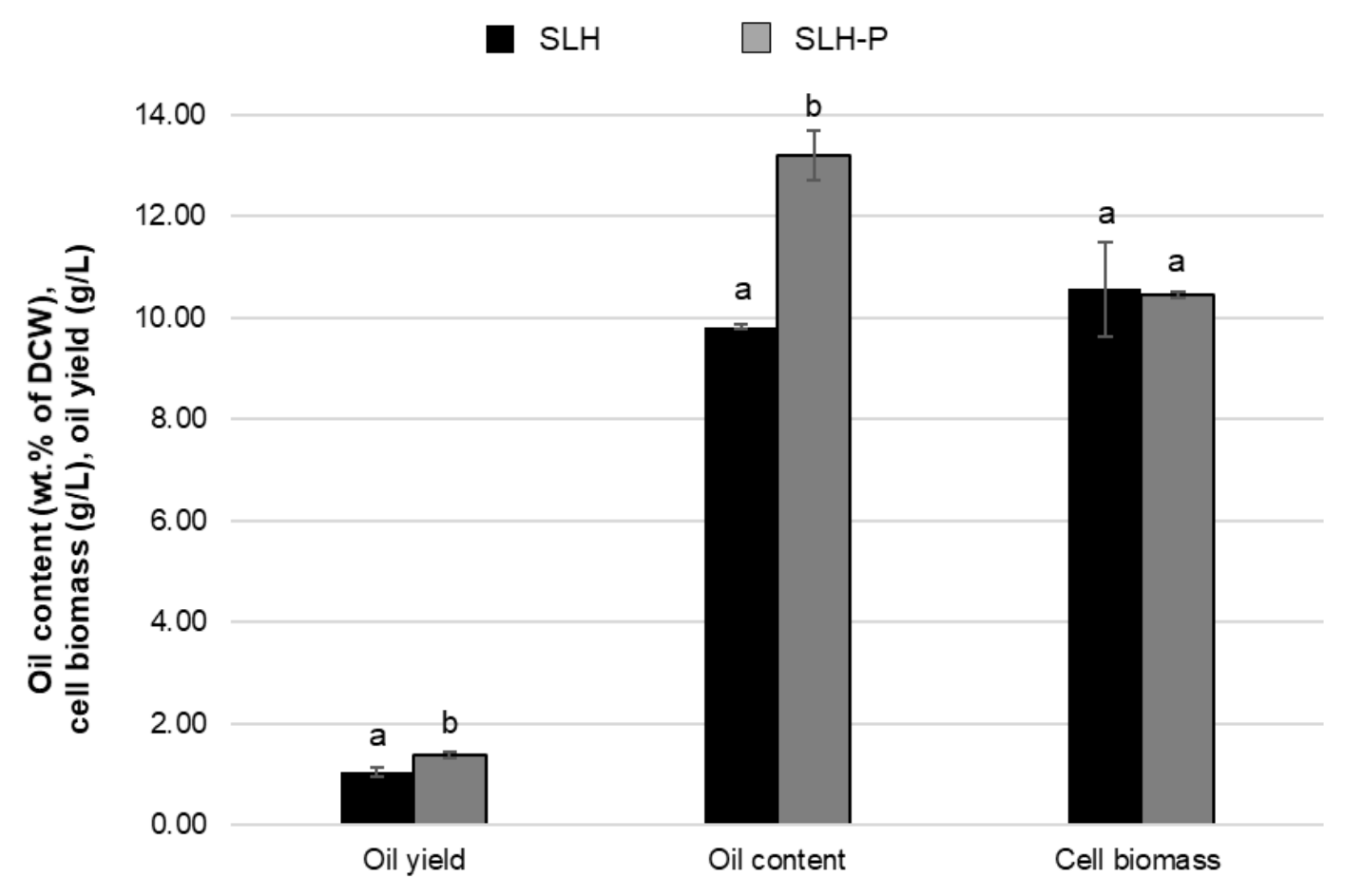

Fig. 2 Comparison of the oil yields, oil contents, and cell biomasses of $C y$. subsufficiens NG8.2 grown in SLH or SLH-P. Data are shown as the mean \pm SD, derived from three separate cultures. Means with a different letter are significantly different $(p<0.05$, one-way analysis of variance (ANOVA)).

These results broadly agree with other studies, where the oil yield and content of Cutaneotrichosporon oleaginosum ATCC 20509 grown in $\mathrm{Ca}(\mathrm{OH})_{2}$-treated water hyacinth hydrolysate supplemented with acetate increased by 4.2 and 4.6 times, respectively, compared to those in untreated hydrolysate (Zhou et al. 2019). The oil yield and content of Cryptococcus curvatus MUCL 29819 were increased from 0.64 to $0.92 \mathrm{~g} / \mathrm{L}$ and from 18.3 $\mathrm{wt} \%$ of DCW to $30.3 \mathrm{wt} \%$ of DCW, respectively, when the $\mathrm{C} / \mathrm{P}$ molar ratio of the OPM was increased from 18 to 1,482 (Huang et al. 2018). When grown in Laminaria residue hydrolysate treated with $\mathrm{Ca}(\mathrm{OH})_{2}(\mathrm{C} / \mathrm{P}$ molar ratio of 1,530), oil yield of Rhodosporidium toruloides Y4 increased by 3.43 times compared to untreated hydrolysate (Zhang et al. 
2016). Likewise, the oil production of Rhodosporidium (formerly known as Rhodotorula) toruloides $\mathrm{Y} 4$ was directly linked to the $\mathrm{C} / \mathrm{P}$ molar ratio of the OPM. When Rhodosporidium toruloides $\mathrm{Y} 4$ was grown in an OPM containing $70 \mathrm{~g} / \mathrm{L}$ of glucose $(\mathrm{C} / \mathrm{N}$ molar ratio of 22.3) with $\mathrm{C} / \mathrm{P}$ molar ratios ranging from 72 to 9,552, the highest oil yield $(2.1 \mathrm{~g} / \mathrm{L})$ and oil content $(62.1 \mathrm{wt} \%$ of DCW) were found when the $\mathrm{C} / \mathrm{P}$ molar ratio was 9,552 (Wu et al. 2010). Oil production of Trichosporon fermantans CICC 1368 in rice straw hydrolysate was significantly improved when the rice straw hydrolysate was treated with $\mathrm{Ca}(\mathrm{OH})_{2}$, concentrated then adsorbed onto Amberlite XAD-4. The oil content and oil yield increased from $11.6 \mathrm{wt} \%$ of DCW to $40.1 \mathrm{wt} \%$ of DCW and from $1.7 \mathrm{~g} / \mathrm{L}$ to 11.5 $\mathrm{g} / \mathrm{L}$, respectively (Huang et al. 2009). The SLH-P was selected as the OPM in next experiment.

The C/P molar ratio of the SLH-P (no added glucose) was further increased from 21,182 to 24,616 and 27,693 by adding glucose at $5 \mathrm{~g} / \mathrm{L}$ and $10 \mathrm{~g} / \mathrm{L}$, respectively. The $C y$. subsufficiens NG8.2 had the highest oil yield (1.33 g/L) and cell biomass $(9.86 \mathrm{~g} / \mathrm{L})$ in the SLH-P with a C/P molar ratio of 21,182 and an oil content of $13.32 \mathrm{wt} \%$ of DCW. When grown in SLH-P with a C/P molar ratio of 24,616 (with $5 \mathrm{~g} / \mathrm{L}$ of glucose), lower biomass $(8.53 \mathrm{~g} / \mathrm{L})$ and oil yield values but a higher oil content $(13.47 \mathrm{wt} \%$ of DCW) were obtained compared to in the SLH-P with a C/P of 21,182 (Fig. 3). These results agreed well with a previous report (Papanikolaou and Aggelis 2011), indicating that excess carbon determined the level of accumulated oil, while a limiting nutrient determined the cell biomass formation. Cutaneotrichosporon oleaginosum ATCC 20509 gave maximum cell biomass $8.2 \mathrm{~g} / \mathrm{L}$ when grown in medium (C/N molar ratio of 12.3) with $\mathrm{C} / \mathrm{P}$ molar ratio of 1360 . Increase of the $\mathrm{C} / \mathrm{P}$ molar ratio of the medium led to a decrease of cell biomass (Zhou et al. 2019).

Almost all of the glucose was consumed within 2 days in the SLH-P with all C/P molar ratios examined. Meanwhile, higher of the C/P molar ratio resulted in lower of the xylose consumption. This might be an effect of the higher osmotic pressure of the increased $\mathrm{C} / \mathrm{P}$ molar ratio-SLH-P by adding glucose. The highest xylose uptake was observed in SLH-P with C/P molar ratio of 21,182 (Fig. 4). The oil yield and content of Trichosporon fermentans CICC 1368 grown in lipid production medium containing $70 \mathrm{~g} / \mathrm{L}$ of fructose $(\mathrm{C} / \mathrm{N}$ molar ratio of 23$)$ increased when the $\mathrm{C} / \mathrm{P}$ molar ratio was increased from 88 to 31,709 , while the cell biomass and fructose consumption decreased, and the optimal $\mathrm{C} / \mathrm{P}$ molar ratio was 6,342 (Bao et al. 2018). The SLH-P with a C/P molar ratio of 21,182 (no added glucose) was used in the next experiment.

The SLH-P contained $1.9 \mathrm{mg} / \mathrm{L}$ or $78 \mu \mathrm{M}$ of $\mathrm{Mg}^{2+}$, which was significantly lower than in the high C/N OPM (49 mg/L) (Table 3). In this experiment, $\mathrm{MgSO}_{4} \cdot 7 \mathrm{H}_{2} \mathrm{O}$ was added at $0.5 \mathrm{~g} / \mathrm{L}, 0.75 \mathrm{~g} / \mathrm{L}$, and $1.0 \mathrm{~g} / \mathrm{L}$ into the $\mathrm{SLH}-\mathrm{P}$ to increase the $\mathrm{Mg}^{2+}$ concentration to $2.11 \mathrm{mM}, 3.12 \mathrm{mM}$, and $4.13 \mathrm{mM}$, respectively, and it was then used as the OPM. The Cy. subsufficiens NG8.2 exhibited the highest oil yield (1.58 g/L) and content $14.81 \mathrm{wt} \%$ of DCW) when the SLH-P contained $3.12 \mathrm{mM}$ of $\mathrm{Mg}^{2+}$, but all added $\mathrm{MgSO}_{4} \cdot 7 \mathrm{H}_{2} \mathrm{O}$ concentrations had no significant effects on the cell biomass formation (Fig. 5).

The $\mathrm{Mg}^{2+}$ concentration influenced the growth and oil production of Trichosporon cutaneum $\mathrm{CH} 002$ grown in corncob hydrolysate, where the highest oil content and cell biomass were obtained with $0.3 \mathrm{~g} / \mathrm{L}$ and $0.4 \mathrm{~g} / \mathrm{L}$ of $\mathrm{MgSO}_{4} \cdot 7 \mathrm{H}_{2} \mathrm{O}$, respectively (Chen et al. 2013). Oil production by Yarrowia lipolytica ACA-DC 50109 under the double limitation of $\mathrm{Mg}^{2+}$ and nitrogen deficiencies was higher than under each individual limitation. 
(a)

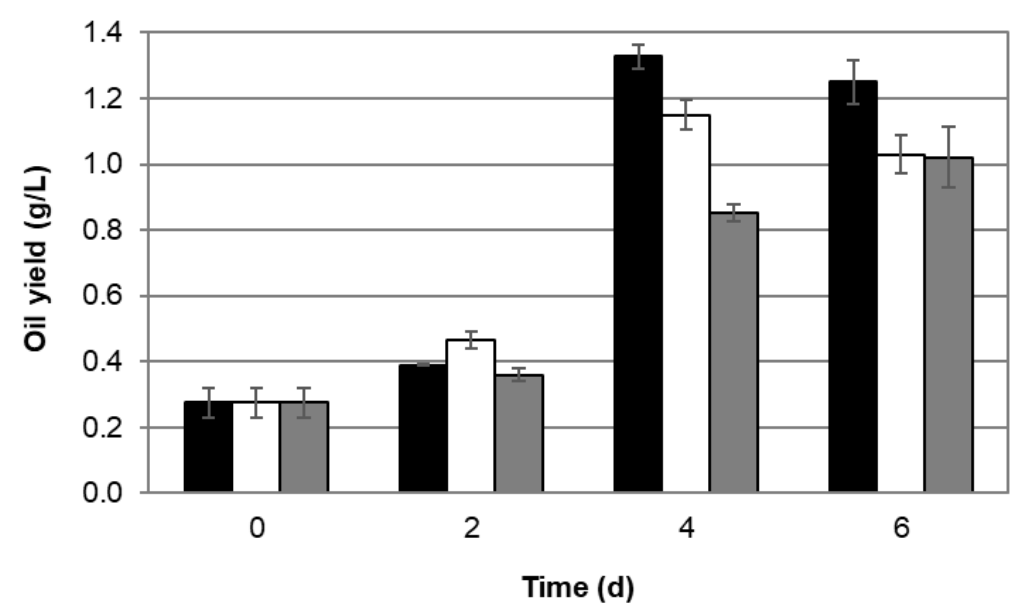

(b)

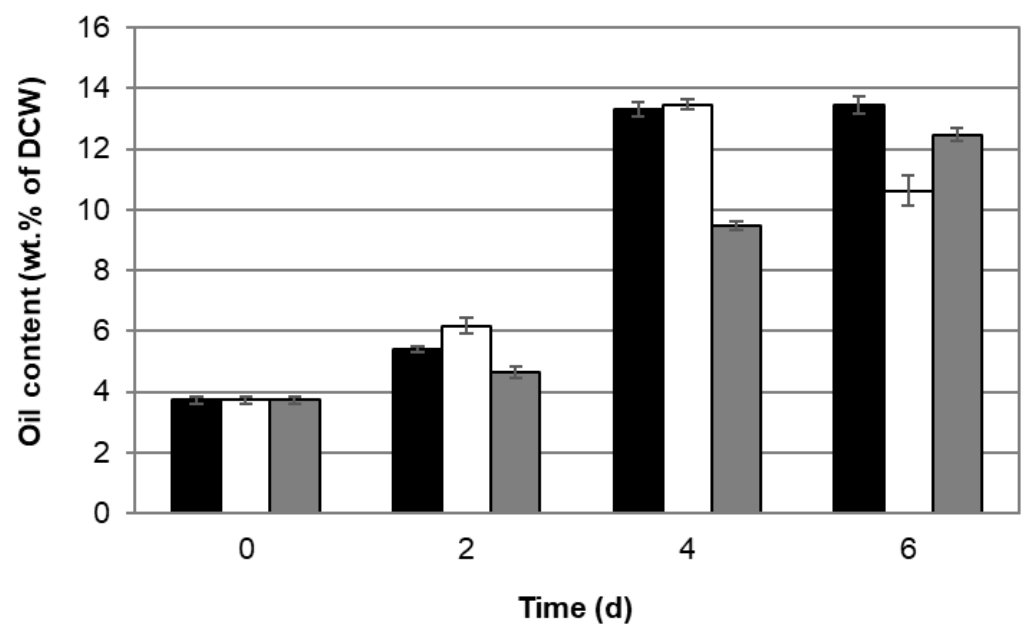

(c)

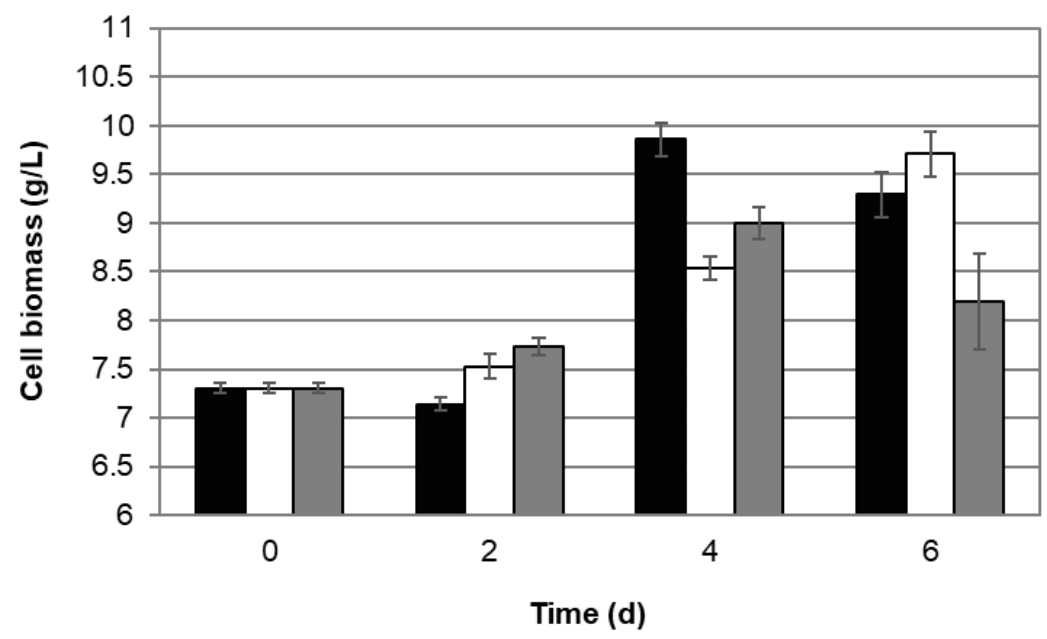

Fig. 3. Comparison of the (a) oil yields, (b) oil contents, and (c) cell biomasses of Cy. subsufficiens

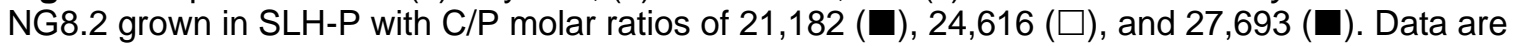
shown as the mean $\pm S D$, derived from three separate cultures for each parameter. 


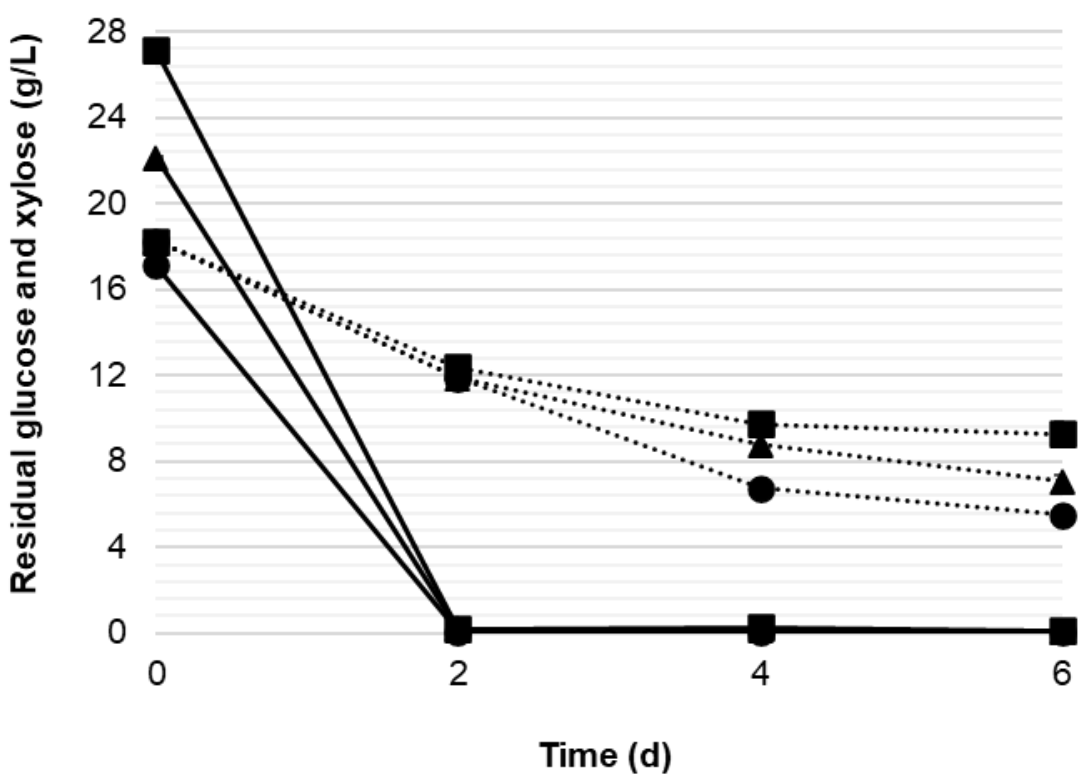

Fig. 4. Glucose (solid line) and xylose (dotted line) consumption profiles of $C y$. subsufficiens NG8.2

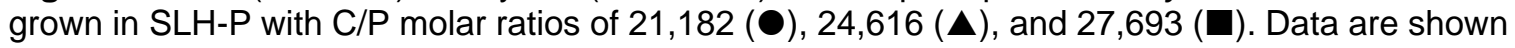
as the mean $\pm S D$, derived from three separate cultures for each parameter.

Under the double limitation, the activities of both ACL and ME were lower than under each individual limitation condition, although there were no significant differences in the transcription levels of ACL or ME (Bellou et al. 2016). The SLH-P containing 3.12 $\mathrm{mM}$ of $\mathrm{Mg}^{2+}$, by supplementation with $75 \mathrm{mg} / \mathrm{L} \mathrm{MgSO}_{4} \cdot 7 \mathrm{H}_{2} \mathrm{O}$, was used as the OPM in the next experiment.

(a)

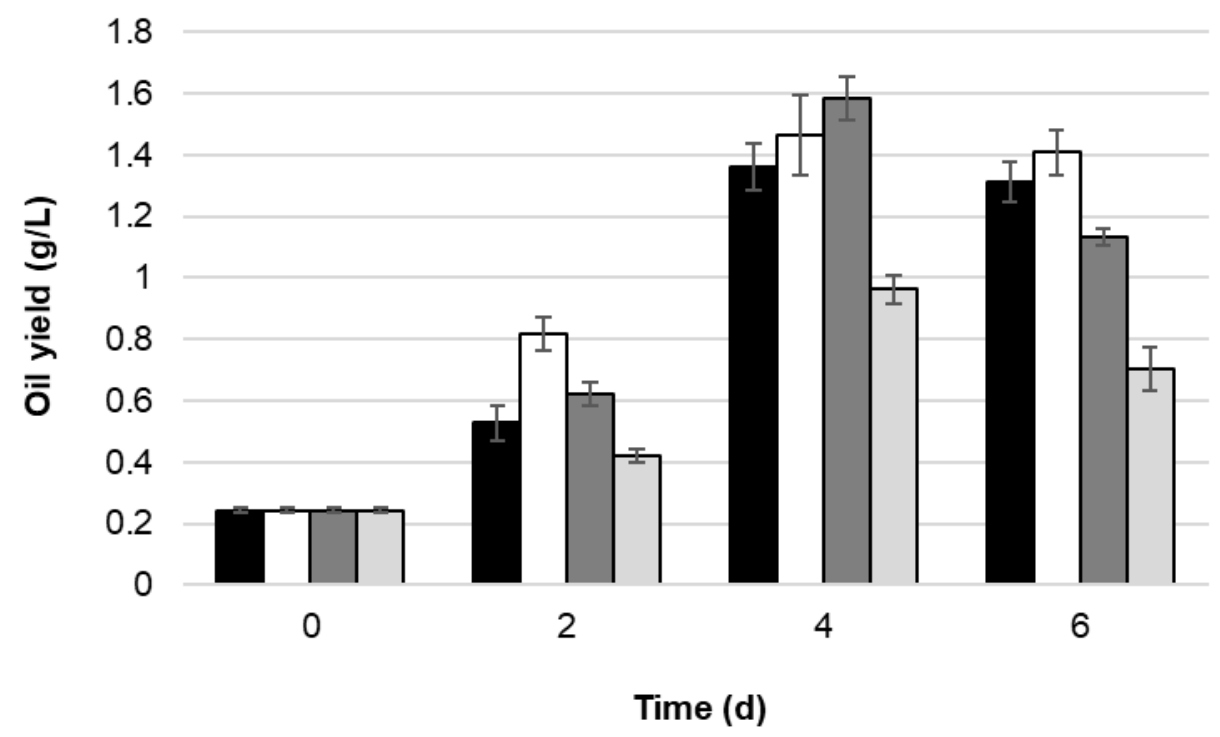

Hoondee et al. (2021). "Production of palmitoleic acid," BioResources 16(2), 2472-2490. 2482 
(b)

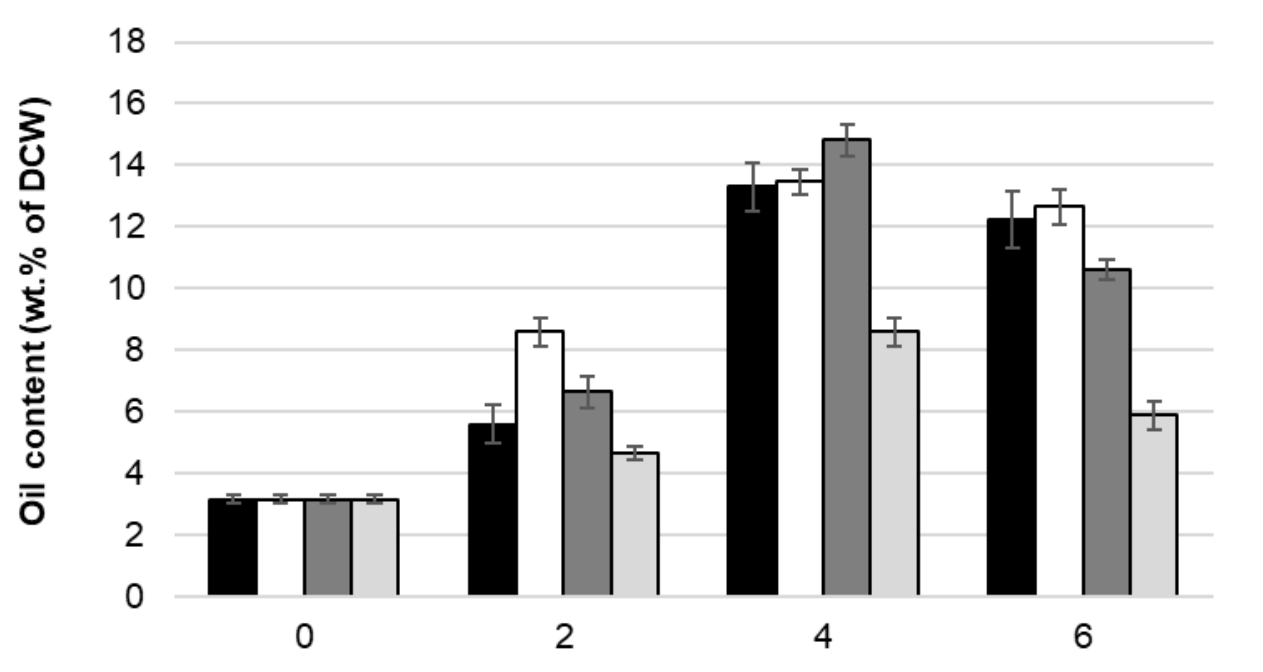

Time (d)

(c)

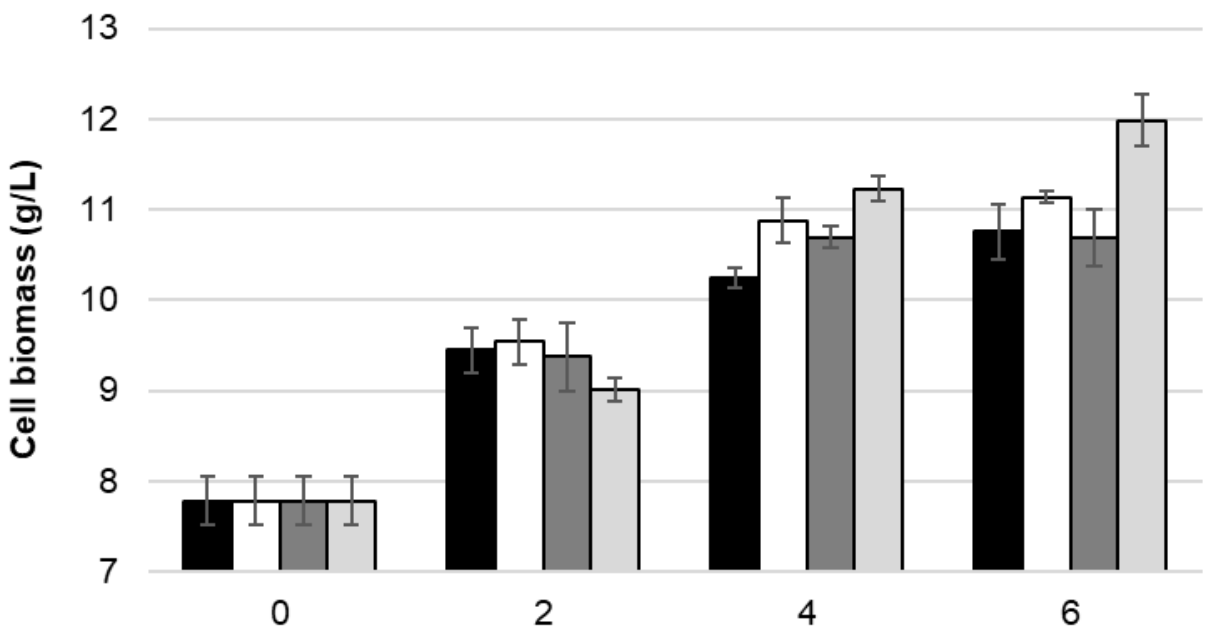

Time (d)

Fig. 5. Comparison of the (a) oil yields, (b) oil contents, (c) and cell biomasses of $C y$. subsufficiens NG8.2 grown in SLH-P containing $0.078 \mathrm{mM}$ of $\mathrm{Mg}^{2+}(\mathbf{\bullet}), 2.11 \mathrm{mM}$ of $\mathrm{Mg}^{2+}(\mathbf{\Delta}), 3.12 \mathrm{mM}$ of $\mathrm{Mg}^{2+}$

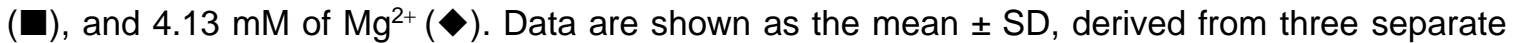
cultures for each parameter.

The Cy. subsufficiens NG8.2 had the highest oil yield (1.59 g/L) and oil content (14.86 wt\% of DCW) in the OPM at a pH of 5.5 at $4 \mathrm{~d}$. The cell biomass was the lowest $(10.69 \mathrm{~g} / \mathrm{L})$ at a $\mathrm{pH}$ of 5.5 but highest $(11.69 \mathrm{~g} / \mathrm{L})$ at a $\mathrm{pH}$ of 6 (Fig. 6). In accordance, a lower $\mathrm{pH}$ was previously found to support oil accumulation in oleaginous yeasts (Patel et al. 2016). Reduced citric acid efflux at acidic pH's might be the reason why lipid production increased (Zhang et al. 2019). 
(a)

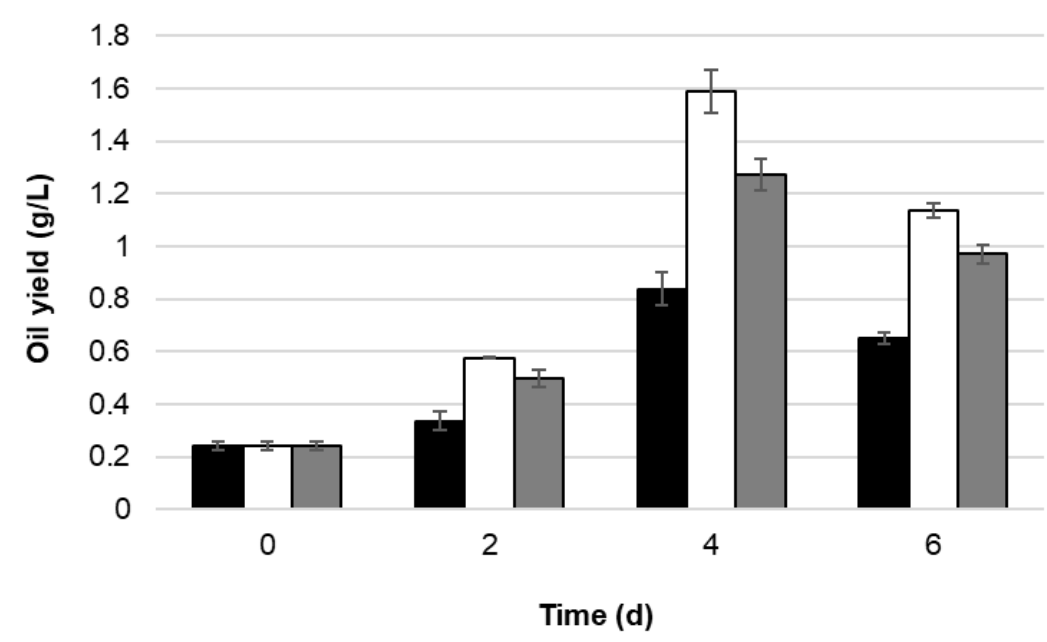

(b)

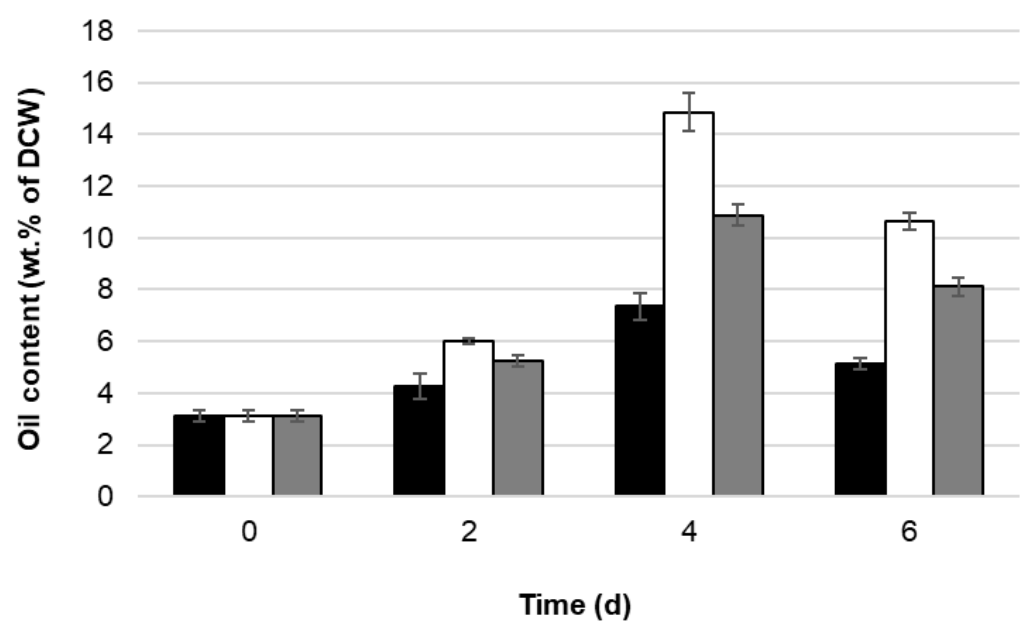

(c)

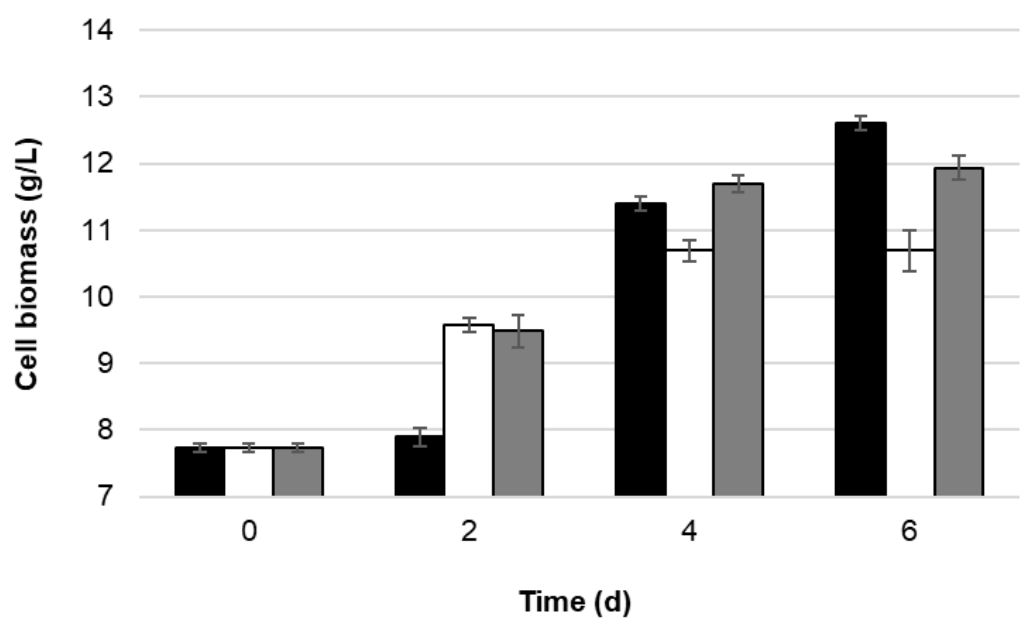

Fig. 6. Comparison of the (a) oil yields, (b) oil contents, and (c) cell biomasses of Cy. subsufficiens NG8.2 grown in SLH-P containing $3.12 \mathrm{mM}$ of $\mathrm{Mg}^{2+}$ at $\mathrm{pH} 4.5(\boldsymbol{O}), 5.5(\mathbf{\Delta})$, and 6 ( $\left.\mathbf{\square}\right)$. Data are shown as the mean $\pm \mathrm{SD}$, derived from three separate cultures for each parameter. 
The optimum $\mathrm{pH}$ for oil production by Rhodosporidium toruloides DMKU3-TK16 in nitrogen-limited OPM containing $30 \mathrm{~g} / \mathrm{L}$ of glucose is 5.5 (Kraisintu et al. 2010). When grown in beet molasses in a $\mathrm{pH}$ range of 4 to 7 , Cutaneotrichosporon (formerly Cryptococcus) curvatus had the highest oil yield $(1.7 \mathrm{~g} / \mathrm{L}$ ) at a pH of 5.5 (El-Fadaly et al. 2009). Rhodotorula kratochvilovae SY89 had the highest oil content (56.06 wt\% of DCW) in an optimized nitrogen-limited OPM containing $50 \mathrm{~g} / \mathrm{L}$ of glucose at a pH of 5.5 (Jiru et al. 2017). Having an optimal $\mathrm{pH}$ for oil production in the acidic range is an advantage for industrial yeast oil production due to the reduction in bacterial contamination (Sitepu et al. 2014).

\section{Fatty Acid Composition of Cy. subsufficiens NG8.2 Oil Produced in SLH}

The amount of accumulated oil and the fatty acid profile are highly dependent on the carbon source (i.e., glucose and xylose), nutrient limitation (i.e., $\mathrm{N}$ or P), cultivation conditions (temperature and $\mathrm{pH}$ ), cultivation time, and setup conditions (batch or fed-batch cultivation) (Kolouchová et al. 2016). Therefore, the fatty acid profiles of Cy. subsufficiens NG8.2 oils produced in SLH, SLH-P, and SLH-P containing $3.12 \mathrm{mM}$ of $\mathrm{Mg}^{2+}$ (pH 5.5) for $4 \mathrm{~d}$ were compared. The results revealed that the major fatty acids in the oil produced in the SLH were oleic, palmitic, and palmitoleic acids, while those produced in the SLH-P and SLH-P containing $3.12 \mathrm{mM}$ of $\mathrm{Mg}^{2+}$ were palmitic, oleic, and palmitoleic acids. The palmitoleic acid content in the oil decreased from $18.73 \mathrm{wt} \%$ (in SLH) to $12.45 \mathrm{wt} \%$ (in SLH-P) when the C/P molar ratio increased from 194 in the SLH to 21,182 in the SLH-P (Table 4).

In accordance with these results, the palmitoleic acid contents in oils of Yarrowia lipolytica CCY 29-26-36 and Candida krusei DBM 2163 produced in two oil production media, which had the same $\mathrm{C} / \mathrm{N}$ molar ratio (30) but different $\mathrm{C} / \mathrm{P}$ molar ratios $(6$ and 1043), decreased from $16.4 \mathrm{wt} \%$ to $14.9 \mathrm{wt} \%$ and from $16.0 \mathrm{wt} \%$ to $14.4 \mathrm{wt} \%$, respectively, when the C/P molar ratio of the OPM increased (Kolouchová et al. 2015). The palmitoleic acid content in the oil from Cutaneotrichosporon (formerly, Cryptococcus) curvatus MUCL 29819 decreased from $16.77 \mathrm{wt} \%$ to $12.64 \mathrm{wt} \%$ when the C/P molar ratio of the OPM was increased from 18 to 1482 (Huang et al. 2018).

In this study, the addition of $0.75 \mathrm{~g} / \mathrm{L}$ of $\mathrm{MgSO}_{4} \cdot 7 \mathrm{H}_{2} \mathrm{O}$ into the SLH-P increased the proportions of palmitic and palmitoleic acids but decreased the oleic acid content in the Cy. subsufficiens NG8.2 oil. Palmitic acid is catalyzed by fatty acyl CoA synthetase to palmitoyl-CoA, and the palmitoyl-CoA is then converted to palmitoleic acid by delta- 9 desaturase. These fatty acyl CoA synthetase require $\mathrm{Mg}^{2+}$ for activity (Cook and McMaster 1996). The palmitoleic acid content was greatest (15.80 wt\%) in the oil produced in the SLH-P containing $3.12 \mathrm{mM}$ of $\mathrm{Mg}^{2+}$ (Table 4).

Several factors in combination, including the oil content, cell biomass, and palmitoleic acid content of the oil produced, determined the palmitoleic acid yield. The SLH-P containing $3.12 \mathrm{mM}$ of $\mathrm{Mg}^{2+}$ had the highest palmitoleic acid yield $(2.09 \mathrm{mg} / \mathrm{g} \mathrm{DW}$ sugarcane leaves), while those of the SLH and SLH-P were lower (1.54 mg/g DW sugarcane leaves and $1.43 \mathrm{mg} / \mathrm{g} \mathrm{DW}$ sugarcane leaves, respectively). The $\mathrm{C} / \mathrm{N}$ molar ratio of OPM was the main factor affected palmitoleic acid yield of oleaginous yeasts. Palmitoleic acid yields of Candida krusei DBM 2163, Yarrowia lipolytica CCY 29-26-36, and Trichosporon cutaneum CCY 30-5-10 were highest at 430, 260, and $80 \mathrm{mg} / \mathrm{g}$ DCW, respectively when $\mathrm{C} / \mathrm{N}$ molar ratio of OPM was increased from 3 to 30 (Kolouchová et al. 2015). Trichosporon cutaneum CCY 30-5-10 gave maximum palmitoleic acid yield (over

Hoondee et al. (2021). "Production of palmitoleic acid," BioResources 16(2), 2472-2490. 2485 
$285 \mathrm{mg} / \mathrm{g} \mathrm{DCW})$ in OPM (C/N molar ratio of 70) having ammonium sulfate as nitrogen source (Kolouchová et al. 2016).

Table 4. Fatty Acid Profiles of Cy. subsufficiens NG8.2 Oil Produced in SLH, SLH-P, or SLH-P Containing $3.12 \mathrm{mM}$ of $\mathrm{Mg}^{2+}(\mathrm{pH} 5.5)$ for $4 \mathrm{~d}$

\begin{tabular}{|c|c|c|c|}
\hline \multirow{2}{*}{ Fatty Acid } & \multicolumn{3}{|c|}{ Percentage (wt\%) } \\
\cline { 2 - 4 } & $12 \%-S L H$ & $12 \%-S L H-P$ & $\begin{array}{c}12 \%-S L H-P \text { with } \\
3.12 \mathrm{mM} \mathrm{of} \mathrm{Mg}^{2+}\end{array}$ \\
\hline Myristic acid (C14:0) & $1.00 \pm 0.01$ & $1.37 \pm 0.05$ & $1.79 \pm 0.11$ \\
\hline Palmitic acid (C16:0) & $28.10 \pm 2.31$ & $42.71 \pm 0.43$ & $46.59 \pm 1.35$ \\
\hline Palmitoleic acid (C16:1) & $18.73 \pm 1.88$ & $12.45 \pm 0.70$ & $15.80 \pm 0.43$ \\
\hline Steric acid (C18:0) & $2.46 \pm 0.07$ & $2.37 \pm 0.70$ & $3.31 \pm 1.00$ \\
\hline Oleic acid(C18:1) & $31.69 \pm 1.10$ & $31.62 \pm 0.37$ & $24.42 \pm 0.24$ \\
\hline Linoleic acid (C18:2) & $14.52 \pm 0.35$ & $7.08 \pm 0.09$ & $4.57 \pm 0.14$ \\
\hline Others & 3.51 & 2.42 & 3.51 \\
\hline Data are shown as the mean \pm SD, derived from three independent repeats. \\
\hline
\end{tabular}

\section{CONCLUSIONS}

1. Sugarcane leaves hydrolysate (SLH) had potential as raw material for palmitoleic acid production using Cyberlindnera (Cy.) subsufficiens NG8.2.

2. Treatment of the $\mathrm{SLH}$ with $\mathrm{Ca}\left(\mathrm{OH}_{2}\right)$ increased the $C y$. subsufficiens NG8.2 oil production but decreased palmitoleic acid content of the oil.

3. $\mathrm{Ca}\left(\mathrm{OH}_{2}\right)$-treated SLH (SLH-P) supplemented with $\mathrm{Mg}^{2+}$ increased the $C y$. subsufficiens NG8.2 oil production and palmitoleic acid content of the oil.

4. Cy. subsufficiens NG8.2 grown in the SLH-P supplemented with $3.12 \mathrm{mM}$ of $\mathrm{Mg}^{2+}$ at $\mathrm{pH} 5.5$ and $30^{\circ} \mathrm{C}$, with 200 -rpm aeration, for $4 \mathrm{~d}$ gave maximum palmitoleic acid yield at $2.09 \mathrm{mg} / \mathrm{g}$ DW sugarcane leaves.

\section{ACKNOWLEDGMENTS}

This research was funded by the National Research University Project, Office of Higher Education Commission (WCU-58-016-EN), the $90^{\text {th }}$ Anniversary of Chulalongkorn University Fund (Ratchadaphiseksomphot Endowment Fund), and the Thailand Research Fund through the Royal Golden Jubilee Ph.D. Program (Grant No. PHD/0059/2558). The authors thank Dr. Robert D. J. Butcher, Faculty of Science, Chulalongkorn University, for his assistance in English proofreading and precious comments on the manuscript.

\section{REFERENCES CITED}

Ageitos, J. M., Vallejo, J. A., Veiga-Crespo, P., and Villa, T. G. (2011). "Oily yeasts as oleaginous cell factories," Applied Microbiology and Biotechnology 90, 1219-1227. DOI: $10.1007 / \mathrm{s} 00253-011-3200-\mathrm{z}$ 
Amaretti, A., Raimondi, S., Sala, M., Roncaglia, L., De Lucia, M., Leonardi, A., and Rossi, M. (2010). "Single cell oils of the cold-adapted oleaginous yeast Rhodotorula glacialis DBVPG 4785," Microbial Cell Factories 9. DOI: 10.1186/1475-2859-9-73

Angerbauer, C., Siebenhofer, M., Mittelbach, M., and Guebitz, G. M. (2008).

"Conversion of sewage sludge into lipids by Lipomyces starkeyi for biodiesel production," Bioresource Technology 99(8), 3051-3056.

DOI: 10.1016/j.biortech.2007.06.045

Bao, R., Wu, X., Liu, S., Xie, T., Yu, C., and Lin, X. (2018). "Efficient conversion of fructose-based biomass into lipids with Trichosporon fermentans under phosphatelimited conditions," Applied Biochemistry and Biotechnology 184(1), 113-123. DOI: $10.1007 / \mathrm{s} 12010-017-2536-y$

Bellou, S., Triantaphyllidou, I.-E., Mizerakis, P., and Aggelis, G. (2016). "High lipid accumulation in Yarrowia lipolytica cultivated under double limitation of nitrogen and magnesium," Journal of Biotechnology 234, 116-126.

DOI: 10.1016/j.jbiotec.2016.08.001

Bellut, K., Michel, M., Zarnkow, M., Hutzler, M., Jacob, F., Atzler, J. J., Hoehnel, A., Lynch, K. M., and Arendt, E. K. (2019). "Screening and application of Cyberlindnera yeasts to produce a fruity, non-alcoholic beer," Fermentation 5(4).

DOI: 10.3390/fermentation5040103

Chen, X., Li, Z., Zhang, X., Hu, F., Ryu, D. D., and Bao, J. (2009). "Screening of oleaginous yeast strains tolerant to lignocellulose degradation compounds," Applied Biochemistry and Biotechnology 159(3). 591-604. DOI: 10.1007/s12010-008-8491-X.

Chen, X.-F., Huang, C., Yang, X.-Y., Xiong, L., Chen, X.-D., and Ma, L.-L. (2013). "Evaluating the effect of medium composition and fermentation condition on the microbial oil production by Trichosporon cutaneum on corncob acid hydrolysate," Bioresource Technology 143, 18-24. DOI: 10.1016/j.biortech.2013.05.102

Cook, H. W., and McMaster, C. R. (1996). "Fatty acid desaturation and chain elongation in eukaryotes," in: Biochemistry of Lipids, Lipoproteins, and Membranes (4 ${ }^{\text {th }}$ ed.), D. E. Vance and J. E. Vance (eds.), Amsterdam, The Netherlands, pp. 181-204.

Department of Alternative Energy Development and Efficiency (2013). "Potential of biomass in Thailand," (http://biomass.dede.go.th/biomass_web/index.html), Accessed 16 April 2020.

El-Fadaly, H. A., El-Naggar, N. E.-A., and Marwan, E.-S. M. (2009). "Single cell oil production by an oleaginous yeast strain in a low cost cultivation medium," Research Journal of Microbiology 4(8), 301-313. DOI: 10.3923/jm.2009.301.313

Folch, J., Lees, M., and Stanley, G. H. S. (1957). "A simple method for the isolation and purification of total lipides from animal tissues," Journal of Biological Chemistry 226, 497-509.

Griel, A. E., Cao, Y., Bagshaw, D. D., Cifelli, A. M., Holub, B., and Kris-Etherton, P. M. (2008). "A macadamia nut-rich diet reduces total and LDL-cholesterol in mildly hypercholesterolemic men and women," The Journal of Nutrition 138(4), 761-767. DOI: $10.1093 / \mathrm{jn} / 138.4 .761$

Hoondee, P., Wattanagonniyom, T., Weeraphan, T., Tanasupawat, S., and Savarajara, A. (2019). "Occurrence of oleaginous yeast from mangrove forest in Thailand," World Journal of Microbiology and Biotechnology 35(108), 1-17. DOI: 10.1007/s11274019-2680-3

Huang, C., Zong, M. H., Wu, H., and Liu, Q. P. (2009). "Microbial oil production from rice straw hydrolysate by Trichosporon fermentans," Bioresource Technology 
100(19), 4535-4538. DOI: 10.1016/j.biortech.2009.04.022

Huang, X., Luo, H., Mu, T., Shen, Y., Yuan, M., and Liu, J. (2018). "Enhancement of lipid accumulation by oleaginous yeast through phosphorus limitation under high content of ammonia," Bioresource Technology 262, 9-14.

DOI: 10.1016/j.biortech.2018.04.063

Jaiboon, K., Lertwattanasakul, N., Limtong, P., and Limtong, S. (2016). "Yeasts from peat in a tropical peat swamp forest in Thailand and their ability to produce ethanol, indole-3-acetic acid and extracellular enzymes," Mycological Progress 15(7), 755770. DOI: $10.1007 / \mathrm{s} 11557-016-1205-9$

Jiru, T. M., Groenewald, M., Pohl, C., Steyn, L., Kiggundu, N., and Abate, D. (2017). "Optimization of cultivation conditions for biotechnological production of lipid by Rhodotorula kratochvilovae (syn, Rhodosporidium kratochvilovae) SY89 for biodiesel preparation," 3 Biotech 7. DOI: 10.1007/s13205-017-0769-7

Jutakanoke, R., Leepipatpiboon, N., Tolieng, V., Kitpreechavanich, V., Srinorakutara, T., and Akaracharanya, A. (2012). "Sugarcane leaves: Pretreatment and ethanol fermentation by Saccharomyces cerevisiae," Biomass and Bioenergy 39, 283-289. DOI: 10.1016/j.biombioe.2012.01.018

Kitcha, S., and Cheirsilp, B. (2011). "Screening of oleaginous yeasts and optimization for lipid production using crude glycerol as a carbon source," Energy Procedia 9, 274282. DOI: 10.1016/j.egypro.2011.09.029

Kjeldahl, J. (1883). "Neue Methode zur Bestimmung des Stickstoffs in organischen Körpern [A new method for the determination of nitrogen in organic matter]," Zeitschrift für Analytische Chemie 22, 366-382. DOI: 10.1007/BF01338151

Kolouchová, I., Mat’átková, O., Sigler, K., Masák, J., and Řezanka, T. (2016). "Production of palmitoleic and linoleic acid in oleaginous and nonoleaginous yeast biomass," International Journal of Analytical Chemistry 2016. DOI: $10.1155 / 2016 / 7583684$

Kolouchová, I., Sigler, K., Schreiberová, O., Masák, J., and Řezanka, T. (2015). "New yeast-based approaches in production of palmitoleic acid," Bioresource Technology 192, 726-734. DOI: 10.1016/j.biortech.2015.06.048

Kraisintu, P., Yongmanitchai, W., and Limtong, S. (2010). "Selection and optimization for lipid production of a newly isolated oleaginous yeast, Rhodosporidium toruloides DMKU3-TK16," Kasetsart Journal (Natural Sciences) 44(3), 436-445.

Lin, J., Li, S., Sun, M., Zhang, C., Yang, W., Zhang, Z., Li, X, and Li, S. (2014). "Microbial lipid production by oleaginous yeast in D-xylose solution using a twostage culture mode," RSC Advances 4(66), 34944-34949.

DOI: $10.1039 / \mathrm{C} 4 \mathrm{RA} 01453 \mathrm{G}$

Madani, M., Enshaeieh, M., and Abdoli, A. (2017). "Single cell oil and its application for biodiesel production," Process Safety and Environmental Protection 111, 747-756. DOI: 10.1016/j.psep.2017.08.027

Meesters, P., Huijberts, G., and Eggink, G. (1996). "High-cell-density cultivation of the lipid accumulating yeast Cryptococcus curvatus using glycerol as a carbon source," Applied Microbiology and Biotechnology 45, 575-579. DOI: 10.1007/s002530050731

Morgan, N. G., and Dhayal, S. (2010). "Unsaturated fatty acids as cytoprotective agents in the pancreatic $\beta$-cell," Prostaglandins, Leukotrienes and Essential Fatty Acids 82(4-6), 231-236. DOI: 10.1016/j.plefa.2010.02.018

Office of the Cane and Sugar Board (2020). "Report of the sugarcane cultivation situation in the production year 2019/2020," (http://www.ocsb.go.th/upload/journal/ 
fileupload/923-1854.pdf), Accessed 28 September 2020.

Papanikolaou, S., and Aggelis, G. (2011). "Lipids of oleaginous yeasts. Part II:

Technology and potential applications," European Journal of Lipid Science and

Technology 113(8), 1052-1073. DOI: 10.1002/ejlt.201100015

Patel, A., Arora, N., Sartaj, K., Pruthi, V., and Pruthi, P. A. (2016). "Sustainable biodiesel production from oleaginous yeasts utilizing hydrolysates of various non-edible lignocellulosic biomasses," Renewable and Sustainable Energy Reviews 62, 836-855. DOI: 10.1016/j.rser.2016.05.014

Pranimit, R., Hoondee, P., Tanasupawat, S., and Savarajara, A. (2019). "Hydrolysate from phosphate supplemented sugarcane leaves for enhanced oil accumulation in Candida sp. NG17,” BioResources 14(1), 1014-1032 DOI: 10.15376/biores.14.1. 1014-1032

Probst, K. V., Schulte, L. R., Durrett, T. P., Rezac, M. E., and Vadlani, P. V. (2016). "Oleaginous yeast: A value-added platform for renewable oils," Critical Reviews in Biotechnology 36(5), 942-955. DOI: 10.3109/07388551.2015.1064855

Řezanka, T., Matoulková, D., Kolouchová, I., Masák, J., and Sigler, K. (2013). “Brewer’s yeast as a new source of palmitoleic acid-Analysis of triacylglycerols by LC-MS," Journal of the American Oil Chemists' Society 90, 1327-1342. DOI: 10.1007/s11746013-2271-7

Rice, E. W., Baird, R. B., Eaton, A. D., and Clesceri, L. S. (eds.) (2012). Standard Methods for the Examination of Water and Wastewater, $22^{\text {nd }}$ Edition, American Public Health Association, Washington, DC, USA.

Schulze, I., Hansen, S., Großhans, S., Rudszuck, T., Ochsenreither, K., Syldatk, C., and Neumann, A. (2014). "Characterization of newly isolated oleaginous yeastsCryptococcus podzolicus, Trichosporon porosum and Pichia segobiensis," AMB Express 4, 24. DOI: 10.1186/s13568-014-0024-0

Sitepu, I. R., Garay, L. A., Sestric, R., Levin, D., Block, D. E., German, J. B., and Boundy-Mills, K. L. (2014). “Oleaginous yeasts for biodiesel: Current and future trends in biology and production," Biotechnology Advances 32(7), 1336-1360. DOI: 10.1016/j.biotechadv.2014.08.003

TAPPI T203 cm-99 (2009). "Alpha-, beta- and gamma-cellulose in pulp," TAPPI Press, Atlanta, GA, USA.

TAPPI T221 om-02 (2002). "Ash in wood, pulp, paper and paperboard: Combustion at $525^{\circ} \mathrm{C}$," TAPPI Press, Atlanta, GA, USA.

TAPPI T222 om-15 (2015). “Acid-insoluble lignin in wood and pulp,” TAPPI Press, Atlanta, GA, USA.

Wang, Y., Zhang, S., Zhu, Z., Shen, H., Lin, X., Jin, X., Jiao, X., and Zhao, Z. K. (2018). "Systems analysis of phosphate-limitation-induced lipid accumulation by the oleaginous yeast Rhodosporidium toruloides," Biotechnology for Biofuels 11. DOI: $10.1186 / \mathrm{s} 13068-018-1134-8$

Wille, J. J., and Kydonieus, A. (2003). "Palmitoleic acid isomer (C16:1 $\Delta 6)$ in human skin sebum is effective against Gram-positive bacteria," Skin Pharmacology and Physiology 16(3), 176-187. DOI: 10.1159/000069757

Wu, S., Hu, C., Jin, G., Zhao, X., and Zhao, Z. K. (2010). "Phosphate-limitation mediated lipid production by Rhodosporidium toruloides," Bioresource Technology 101(15), 6124-6129. DOI: 10.1016/j.biortech.2010.02.111

Xia, Z., Li, L., Feng, S., Cheng, H., and Wei, H. (2016). "Clarifying the remelt syrup of brown granulated sugar by phosphate flocculating process," Chemical Industry and 
Engineering Progress (7), 2015-2020.

Yu, X., Zheng, Y., Dorgan, K. M., and Chen, S. (2011). "Oil production by oleaginous yeasts using the hydrolysate from pretreatment of wheat straw with dilute sulfuric acid," Bioresource Technology 102(10), 6134-6140.

DOI: 10.1016/j.biortech.2011.02.081

Zhang, S., Jagtap, S. S., Deewan, A., and Rao, C. V. (2019). "pH selectively regulates citric acid and lipid production in Yarrowia lipolytica W29 during nitrogen-limited growth on glucose," Journal of Biotechnology 290, 10-15.

DOI: $10.1016 /$ j.jbiotec.2018.10.012

Zhang, X., Shen, H., Yang, X., Wang, Q., Yua, X., and Zhao, Z. K. (2016). "Microbial lipid production by oleaginous yeasts on Laminaria residue hydrolysates," RSC Advances 6(32), 26752-26756. DOI: 10.1039/c6ra00995f

Zhou, W., Tang, M., Zou, T., Peng, N., Zhao, M., and Gong, Z. (2019). “Phosphate removal combined with acetate supplementation enhances lipid production from water hyacinth by Cutaneotrichosporon oleaginosum," Biotechnology for Biofuels 12(1). DOI: 10.1186/s13068-019-1491-y

Article submitted: November 25, 2020; Peer review completed: January 2, 2021; Revised version received: February 6, 2021; Published: February 9, 2021.

DOI: 10.15376/biores.16.2.2472-2490 